\title{
The lipids of buffalo spermatozoa and seminal plasma
}

\author{
Y. C. Jain and S. R. Anand \\ National Dairy Research Institute, Karnal-132001, India
}

\begin{abstract}
Summary. Lipids were extracted from the spermatozoa and seminal plasma of buffalo and were analysed by column and thin-layer chromatography. Buffalo spermatozoa (10 $10^{9}$ cells) contained $1.15 \mathrm{mg}$ total lipids, $0.285 \mathrm{mg}$ neutral lipids, $0.396 \mathrm{mg}$ glycolipids, $0.547 \mathrm{mg}$ phospholipids and $0.015 \mathrm{mg}$ gangliosides. The corresponding values for $1 \mathrm{ml}$ seminal plasma were: $1.50,0.439,0.581,0.594$ and $0.010 \mathrm{mg}$. The sperm neutral lipids were comprised of $3.2 \%$ hydrocarbons, $4.5 \%$ cholesterol esters, $46.7 \%$ triglycerides, $17 \cdot 5 \%$ 1,3-diglycerides, $3 \cdot 1 \% 1,2$-diglycerides, $17 \cdot 6 \%$ cholesterol, $0.6 \%$ free fatty acids and $2.4 \%$ monoglycerides. The corresponding values for seminal plasma were: $4 \cdot 2,6 \cdot 2,33 \cdot 0,19 \cdot 8,4 \cdot 2,18 \cdot 5,3 \cdot 8$ and $4 \cdot 7 \%$. In the sperm phospholipids, there was $30.4 \%$ phosphatidyl choline; $19.4 \%$ phosphatidal choline; $10.8 \%$ phosphatidyl ethanolamine; $3.4 \%$ phosphatidal ethanolamine; $11.3 \%$ sphingomyelin; $1.5 \%$ phosphatidyl serine; $0.6 \%$ phosphatidyl inositol; $3.9 \%$ lysophosphatidyl choline; $4.4 \%$ lysophosphatidyl ethanolamine; $0.7 \%$ lysophosphatidyl serine; $5.5 \%$ diphosphatidyl glycerol and $0.3 \%$ phosphatidic acid. The corresponding values for seminal plasma were: $21 \cdot 7,17 \cdot 3,11 \cdot 7,4 \cdot 1,13 \cdot 1,2 \cdot 8,3 \cdot 9,5 \cdot 6,1 \cdot 0,7 \cdot 4$ and $0.5 \%$. Comparative data for bull spermatozoa and seminal plasma were also obtained.
\end{abstract}

\section{Introduction}

The composition and metabolism of lipids in semen have been investigated for the bull (Komarek, Pickett, Lanz \& Jensen, 1964; Pursel \& Graham, 1967), ram (Lovern, Olley, Hartree \& Mann, 1957), boar (Komarek, Pickett, Gibson \& Jensen, 1965a; Johnson, Gerrits \& Young, 1969), stallion (Komarek, Pickett, Gibson \& Lanz, 1965b), goat (Jain \& Anand, 1975b) and man (Poulos \& White, 1973). There are only two reports of lipids in buffalo semen (Jain \& Anand, 1975a; Guraya \& Sidhu, 1975). In view of the role lipids play in sperm physiology and metabolism, the lipid composition of buffalo semen was determined and compared with that of bull semen.

\section{Materials and Methods}

\section{Materials}

Silicic acid, 100 mesh, was purchased from Fluka, Buchs, Switzerland, and Silica gel G was the product of E. Merck, Darmstadt, Germany. All the solvents and other chemicals were of analytical reagent grade. The solvents were freshly distilled or purified before use. Unless otherwise stated, all the solvents were evaporated under vacuum at $40^{\circ} \mathrm{C}$. The lipid standards were obtained from Sigma, U.S.A. or the Biochemical Unit, V.P. Chest Institute, Delhi.

\section{Semen collection and extraction of lipids}

Semen was collected by an artificial vagina and ejaculates with high motility from 3 or 4 bulls of each species were pooled. The spermatozoa were separated from the seminal plasma by centrifugation at $3000 \mathrm{~g}$ for $15 \mathrm{~min}$ at $5^{\circ} \mathrm{C}$. The sperm pellet was washed with $\mathrm{Ca}^{++}$-free $\mathrm{Krebs}-\mathrm{Ringer}$ 
phosphate buffer and the washings added to the seminal plasma. The washed spermatozoa were ground in a pestle and mortar with small volumes of chloroform and methanol $(2: 1 \mathrm{v} / \mathrm{v})$ and the slurry was taken up in 20 vols of the same solvent in a conical flask. The lipids were extracted at room temperature under $\mathrm{N}_{2}$ for $12 \mathrm{hr}$ with occasional shaking. The solvent was filtered on a Buchner funnel and the residue was extracted twice more with 5 vols of solvent for 6 and $3 \mathrm{hr}$. The three extracts were combined and then washed with 0.2 vol. $0.37 \% \mathrm{KCl}$ (Folch, Lees \& Sloane-Stanley, 1957). After standing, two phases were obtained; the lower organic layer containing the lipid was removed and the upper water phase was washed twice with $0 \cdot 1$ vol. of the pure solvent lower phase of the Folch system. The lipid extract was dried over anhydrous $\mathrm{Na}_{2} \mathrm{SO}_{4}$. The solvent was evaporated and the total lipids estimated gravimetrically. The lipids of seminal plasma were extracted as described for spermatozoa.

\section{Fractionation of total lipids}

These were fractionated into neutral, glyco- and phospholipids by silicic acid column chromatography (Renkonen, Gamberg, Simons \& Kaariainen, 1972). A slurry of activated silicic acid (12 hr at $\left.105^{\circ} \mathrm{C}\right)$ in hexane was poured into a glass tube $(1.8 \times 40 \mathrm{~cm})$ to a height of $15 \mathrm{~cm}$. The column was washed successively with $100 \mathrm{ml}$ each of hexane, ethyl ether and chloroform. Lipids ( $50 \mathrm{mg}$ in $2.5 \mathrm{ml}$ chloroform) were applied to the adsorbent and the column developed with 1.5 litres chloroform, 4 litres acetone and 2 litres methanol. The solvents were evaporated and the weight of each class of lipid was determined.

\section{Separation of lipid classes into component lipids}

This was achieved by thin-layer chromatography using a $0.5 \mathrm{~mm}$ thick layer of silica gel $\mathrm{G}$ on glass plates and activated at $110^{\circ} \mathrm{C}$ for $1 \mathrm{hr}$. Neutral lipids were separated by the unidimensional double development technique of Freeman \& West (1966) using ethyl ether-benzene-ethanolacetic acid ( $40: 50: 2: 0 \cdot 2$ by vol.) and ethyl ether-hexane $(6: 94 \mathrm{v} / \mathrm{v})$ as the solvents. The phospholipids were separated by the two-dimensional technique of Rouser, Fleischer \& Yamamoto (1970) using chloroform-methanol- $25 \% \mathrm{NH}_{4} \mathrm{OH}(65: 25: 5$ by vol.) in the first direction and chloroformacetone-methanol-acetic acid-water $(60: 80: 20: 20: 10$ by vol.) in the second direction. For the estimation of plasmalogen, the 'separation-reaction-separation' technique of Vishwanathan, Philips \& Lundburg (1968) was employed. After the separation of phospholipids in the first direction, the plate was exposed to $\mathrm{HCl}$ fumes for $4 \mathrm{~min}$ and then was neutralized by ammonia vapour. The plate was flushed with nitrogen for $1 \mathrm{hr}$ and developed in the second direction. The 2-acyl lyso forms were separated from di-acyl analogues and represented the plasmalogen content.

\section{Identification and characterization of spots}

Visualization was effected by spraying the plates with $40 \%$ sulphuric acid and charring at $180^{\circ} \mathrm{C}$ for $30 \mathrm{~min}$. The mobilities of unknown spots were compared with those of authentic samples run under identical conditions. In addition, use of specific spray reagents was made. Phosphorus compounds were detected by molybdate-hydrazine spray (Vaskovsky \& Svetaschev, 1972), amino lipids by ninhydrin (Dittmer \& Lester, 1964), hydroxy compounds by ammoniacal silver nitrate (Skidmore \& Entenman, 1962), choline by Dragendorff's reagent (Kariyone \& Hoshimoto, 1951) and aldehydogenic lipids by Schiff's reagent (Kates, 1967) and 2:4 dinitrophenyl hydrazine (Schmid \& Mangold, 1966).

\section{Analytical methods}

The dry matter content of spermatozoa, seminal plasma and various lipid classes was determined gravimetrically. The neutral lipids were quantitated by first delineating them on thin-layer plates with iodine vapour. The areas were circumscribed and scraped into a centrifuge vial and assayed 
by the sulphuric acid charring method of Marsh \& Weinstein (1966). The phospholipids were quantified through estimation of their phosphorus content (Ahovcova \& Odavic, 1969) and multiplying by 25 .

\section{Results and Discussion}

The results of all the measurements taken are given in Table 1. Buffalo spermatozoa $(18.46 \%)$ had higher dry matter content than either the seminal plasma (4.73 $\pm 0 \cdot 14)$ or semen $(5.98 \pm 0.18)$. Comparison of these values with those of the bull (Lavon, Volcani \& Dannon, 1968) revealed that the percentage dry matter of buffalo spermatozoa and seminal plasma was lower. The dry matter of buffalo semen was generally within the range of values given by Mann (1960) for other mammalian species.

Table 1. The composition of $10^{9}$ sperm cells and $1 \mathrm{ml}$ seminal plasma from bull and buffalo

\begin{tabular}{lccccc}
\hline & \multicolumn{2}{c}{ Spermatozoa $(\mathrm{mg})$} & & \multicolumn{2}{c}{ Seminal plasma $(\mathrm{mg})$} \\
\cline { 2 - 3 } \cline { 5 - 6 } \multicolumn{1}{c}{ Parameters } & Buffalo & Bull & & Buffalo & Bull \\
\hline Fresh weight & 50.093 & 37.410 & & $1019 \cdot 100$ & 1017.600 \\
Dry weight & 9.247 & N.D. & & 48.203 & N.D. \\
Total lipids & $1 \cdot 147$ & 0.703 & & 1.500 & 2.900 \\
Neutral lipids & 0.286 & 0.164 & & 0.439 & 0.896 \\
Unsaponifiable matter & 0.106 & 0.072 & & 0.176 & 0.313 \\
Glycolipids & 0.397 & 0.154 & & 0.581 & 0.713 \\
Phospholipids & 0.548 & 0.416 & & 0.594 & 1.491 \\
Gangliosides* & 0.015 & 0.004 & & 0.010 & 0.014 \\
\hline
\end{tabular}

N.D. = not determined.

* Calculated from sialic acid content (sialic acid $\times 1.78 \times 4$ ); see Jain \& Anand (1975a).

The total lipids extracted from the lower Folch phase of buffalo spermatozoa represented $12.41 \%$ on a dry weight basis. This was in agreement with the total lipid content (12\%) of bull and boar semen (Komarek et al., 1964, 1965a). The semen of the stallion (Komarek et al., 1965b) has a higher total lipid content (14\%) and ram semen a lower value of 7-9\% (Lovern et al., 1957). Bull seminal plasma had higher total lipid content than that in buffalo seminal plasma (Table 1). On a dry weight basis, the lipid content of buffalo seminal plasma was $3.17 \%$ and was higher than the value of $1.21 \%$ estimated for bull seminal plasma by Pickett \& Komarek (1967). Buffalo spermatozoa contained more neutral lipids and glycolipids than bull spermatozoa which had a higher proportion of phospholipids. While no differences were observed in the total neutral lipid content of buffalo and bull seminal plasma, the former was rich in glycolipids and the latter in phospholipids. Komarek et al. (1964, $1965 \mathrm{a}, \mathrm{b}$ ) observed $25 \cdot 0-48 \cdot 8 \%$ neutral lipids in the semen of bull, boar and stallion. No report is available on the total glycolipid content in semen for any mammal other than buffalo and bull (Table 1). Phospholipids constituted a higher proportion of the total lipids in bull $(59.1 \%)$ than in buffalo $(47.8 \%$ ) spermatozoa and have been reported to be the major component of total lipids of spermatozoa and seminal plasma of bull (Komarek et al., 1964; Miller, Mayer \& Merilan, 1965; Pursel \& Graham, 1967), boar (Johnson et al., 1969; Komarek et al., 1965a), goat (Jain \& Anand, 1975b), stallion (Komarek et al., 1965b) and man (Poulos \& White, 1973).

\section{Neutral lipids}

As shown in Table 2, 9 compounds were distinguished. The separation between cholesterol and diglyceride spots by the technique of Freeman \& West (1966) was not sharp and the monoglycerides did not migrate much from the base line. Hydrocarbon moved with the solvent front when double development was used. One compound, a faint spot, had slightly less chromatographic mobility 
Table 2. Quantitative distribution of individual neutral lipid classes as $\%$ of total neutral lipids (mean \pm S.E.M, $n=6$ ) of buffalo and bull spermatozoa and seminal plasma

\begin{tabular}{|c|c|c|c|c|}
\hline \multirow[b]{2}{*}{ Components } & \multicolumn{2}{|c|}{ Spermatozoa } & \multicolumn{2}{|c|}{ Seminal plasma } \\
\hline & Buffalo & Bull & Buffalo & Bull \\
\hline Hydrocarbons & $3 \cdot 2 \pm 0 \cdot 3$ & $5 \cdot 3 \pm 0 \cdot 8$ & $4 \cdot 2 \pm 0.5$ & $5 \cdot 1 \pm 1 \cdot 0$ \\
\hline Cholesterol esters & $4.5 \pm 0.2$ & $4 \cdot 2 \pm 0.2$ & $6.2 \pm 0.6$ & $3.7 \pm 0.2$ \\
\hline Triglycerides & $46.7 \pm 4.4$ & $31.0 \pm 3.3$ & $33 \cdot 0 \pm 2 \cdot 1$ & $40 \cdot 0 \pm 1 \cdot 4$ \\
\hline 1,3-Diglycerides & $17 \cdot 5 \pm 2 \cdot 1$ & $25 \cdot 1 \pm 2 \cdot 1$ & $19 \cdot 8 \pm 1 \cdot 4$ & $19 \cdot 4 \pm 1 \cdot 0$ \\
\hline 1,2-Diglycerides & $3 \cdot 1 \pm 0 \cdot 4$ & $3.9 \pm 0.6$ & $4 \cdot 2 \pm 0 \cdot 3$ & $2 \cdot 0 \pm 0.2$ \\
\hline Cholesterol & $17 \cdot 6 \pm 1.6$ & $19 \cdot 1 \pm 2 \cdot 3$ & $18.5 \pm 0.9$ & $15 \cdot 1 \pm 0.5$ \\
\hline Free fatty acids & $0.6 \pm 0.17$ & $0.7 \pm 0.1$ & $3.8 \pm 0.2$ & $2.4 \pm 0.2$ \\
\hline Monoglycerides & $2.4 \pm 0.5$ & $4 \cdot 8 \pm 0.4$ & $4.7 \pm 0.3$ & $7 \cdot 3 \pm 0 \cdot 7$ \\
\hline $\begin{array}{l}\text { Non-migrating and } \\
\text { uncharacterized }\end{array}$ & $4.4 \pm 0.4$ & $5 \cdot 8 \pm 1 \cdot 0$ & $5 \cdot 7 \pm 0.5$ & $4.9 \pm 0.6$ \\
\hline Total glycerides $(\%)$ & $69 \cdot 7$ & $64 \cdot 8$ & $61 \cdot 7$ & $68 \cdot 7$ \\
\hline $\begin{array}{l}\text { Total cholesterol } \\
\text { (free and bound) (\%) }\end{array}$ & $22 \cdot 1$ & $23 \cdot 3$ & $24 \cdot 7$ & $18 \cdot 8$ \\
\hline
\end{tabular}

than the monoglyceride spot but could not be characterized. Triglycerides were the major component of buffalo and bull semen; $11.63 \%$ for buffalo and $9.6 \%$ for bull spermatozoa and $9.81 \%$ and $12.36 \%$ respectively in seminal plasma. Analysis of the seminal neutral lipids of bull (Miller $e t$ al., 1965; Komarek et al., 1964), boar (Komarek et al., 1965a) and stallion (Komarek et al., 1965b) showed that cholesterol was the major component, followed by triglycerides. The cholesterol content in the three species ranged between 10 and $28 \%$ while we found 3- to 4-fold lower values for buffalo and bull semen. Cholesterol was mainly found as the free sterol with a small amount as sterol esters. Miller et al. (1965) reported $0 \cdot 2 \%$ of the total lipids of bovine semen as cholesterol esters, a value slightly less than that found for buffalo and bull semen in this study. The occurrence of diglycerides in the neutral lipids of bull, boar and stallion has been reported (Miller et al., 1965; Komarek et al., $1964,1965 \mathrm{a}, \mathrm{b})$ but there was no resolution into 1,2- and 1,3-diglycerides. In buffalo and bull, we found that the diglycerides were mainly 1,3-diglycerides. Miller et al. (1965) were unable to demonstrate free fatty acids in bovine semen but we found a small percentage of free fatty acids in buffalo and bull semen. Thus, the neutral lipid composition of the spermatozoa and seminal plasma of the two species studied were qualitatively similar but differed quantitatively, and there were distinct differences compared with findings in other species, particularly in the major component.

\section{Phospholipids}

The phospholipids of buffalo and bull spermatozoa and seminal plasma showed similar chromatographic patterns and the same number of spots on the chromatoplates (Table 3). Three minor spots which contained phosphorus and gave a positive reaction with phospholipid sprays were not characterized because no colour reaction was obtained for bases.

Phosphatidyl choline was the major phospholipid of buffalo spermatozoa and seminal plasma but was at lower concentration in bull and goat (Jain \& Anand, 1975b) seminal lipids. The total choline phosphoglyceride content did not differ much in the sperm lipids but was higher in bull than buffalo and goat seminal plasma. A similar trend was observed for ethanolamine phosphoglycerides in bull and buffalo, but goat sperm lipid contains very little phosphatidal ethanolamine. The high contribution of choline plasmalogens to the total plasmalogen content of the semen $(>78 \%)$ of bull and buffalo agrees with previously published figures for the bull (Pursel \& Graham, 1967), ram (Darin-Bennett, Poulos \& White, 1973) and goat (Jain \& Anand, 1975b), but they differ from those for boar (Johnson et al., 1969) and man (Poulos \& White, 1973) in which ethanolamine plasmalogens are found in larger amounts. Sphingomyelin, phosphatidyl serine, cardiolipin and plasmalogen were reported to be absent in buffalo semen by Guraya \& Sidhu (1975), but their occurrence is definitely established by the present study. 
Table 3. The phospholipid composition ( $\%$ of total phosphorus recovered; mean \pm S.E.M., $n=6$ ) of lipids extracted from the spermatozoa and the seminal plasma of buffalo and bull

\begin{tabular}{|c|c|c|c|c|}
\hline \multirow[b]{2}{*}{ Component } & \multicolumn{2}{|c|}{ Spermatozoa } & \multicolumn{2}{|c|}{ Seminal plasma } \\
\hline & Buffalo & Bull & Buffalo & Bull \\
\hline Phosphatidyl choline & $30 \cdot 4 \pm 1 \cdot 4$ & $17.9 \pm 0.8$ & $21 \cdot 7 \pm 1 \cdot 0$ & $24 \cdot 5 \pm 2 \cdot 2$ \\
\hline $\begin{array}{l}\text { Phosphatidal choline } \\
\text { (choline plasmalogen) }\end{array}$ & $19 \cdot 4 \pm 1 \cdot 7$ & $36 \cdot 8 \pm 1 \cdot 4$ & $17 \cdot 3 \pm 0 \cdot 9$ & $32 \cdot 9 \pm 2 \cdot 0$ \\
\hline Phosphatidyl ethanolamine & $10 \cdot 8 \pm 2 \cdot 0$ & $5 \cdot 3 \pm 0 \cdot 4$ & $11 \cdot 7 \pm 1 \cdot 5$ & $5 \cdot 6 \pm 0 \cdot 4$ \\
\hline $\begin{array}{l}\text { Phosphatidal ethanolamine } \\
\text { (ethanolamine plasmalogen) }\end{array}$ & $3.4 \pm 0.5$ & $9 \cdot 0 \pm 0 \cdot 4$ & $4 \cdot 1 \pm 0 \cdot 3$ & $9 \cdot 0 \pm 0.9$ \\
\hline Sphingomyelin & $11 \cdot 3 \pm 0 \cdot 7$ & $12 \cdot 2 \pm 1 \cdot 2$ & $13 \cdot 1 \pm 0 \cdot 7$ & $11 \cdot 6 \pm 1 \cdot 0$ \\
\hline Phosphatidyl serine & $1 \cdot 5 \pm 0.3$ & $1.7 \pm 0.4$ & $2 \cdot 8 \pm 0.4$ & $1 \cdot 3 \pm 0 \cdot 3$ \\
\hline Phosphatidyl inositol & $0 \cdot 6 \pm 0 \cdot 1$ & $1 \cdot 0 \pm 0 \cdot 2$ & $2.9 \pm 0.5$ & $0.8 \pm 0.2$ \\
\hline Lysophosphatidyl choline & $3.9 \pm 0.5$ & $1.9 \pm 0.5$ & $3.9 \pm 0.9$ & $1 \cdot 2 \pm 0 \cdot 3$ \\
\hline Lysophosphatidyl ethanolamine & $4 \cdot 4 \pm 1 \cdot 0$ & $3 \cdot 2 \pm 0 \cdot 6$ & $5 \cdot 6 \pm 1 \cdot 5$ & $2.4 \pm 0.8$ \\
\hline Lysophosphatidyl serine & $0 \cdot 7 \pm 0 \cdot 1$ & $0.5 \pm 0.1$ & $1 \cdot 0 \pm 0 \cdot 3$ & $0.4 \pm 0.1$ \\
\hline $\begin{array}{l}\text { Diphosphatidyl glycerol } \\
\text { (cardiolipin) }\end{array}$ & $5 \cdot 5 \pm 0 \cdot 7$ & $5.9 \pm 1.0$ & $7 \cdot 4 \pm 1 \cdot 3$ & $5.0 \pm 0.5$ \\
\hline Phosphatidic acid & $0 \cdot 3 \pm 0 \cdot 1$ & $0.2 \pm 0.1$ & $0.5 \pm 0.2$ & $0.4 \pm 0.1$ \\
\hline $\begin{array}{l}\text { Non-migrating and } \\
\text { uncharacterized }\end{array}$ & $7 \cdot 8 \pm 1 \cdot 3$ & $4.4 \pm 0.7$ & $8 \cdot 0 \pm 1 \cdot 1$ & $5 \cdot 0 \pm 0 \cdot 7$ \\
\hline
\end{tabular}

Among the lysophospholipids, the choline form has been reported in bull, ram and boar semen (Clegg \& Foote, 1973; Darin-Bennett et al., 1973; Johnson et al., 1969) but Jain \& Anand (1975b) detected, in addition, the ethanolamine and serine forms in the phospholipids of goat semen. As in the goat, there was more lysophosphatidyl choline and ethanolamine than serine in buffalo and bull seminal phospholipids. The lysophospholipids could have arisen by lipolysis during isolation but this seems unlikely because of their occurrence in appreciable amounts. It is also possible that our technique was more effective in separating endogenous lysophospholipids than the methods employed for other species.

Lardy \& Philips (1941) suggested that, in the absence of glycolysable carbohydrates, bull spermatozoa derive their energy by the oxidation of intracellular phospholipids. It has now been shown that human (Poulos \& White, 1973) and ram (Darin-Bennett et al., 1973) spermatozoa do not use intracellular phospholipids as a source of oxidizable substrate in a sugar-free medium. It would be interesting to study buffalo spermatozoa in this way because they sustain endogenous respiration for long periods (Gandhi \& Anand, 1975) and also contain much glycolipid and phospholipid. Phospholipids are also important structural components of membranes. The structural integrity of plasma and other membranes of the sperm cell is an important factor during the freezing of semen. In contrast to bull spermatozoa, buffalo spermatozoa do not maintain their fertilizing ability when semen is deep frozen (Singh, 1967) and this may be due to the compositional differences revealed in the present study.

We thank the Director, Dr D. Sundaresan, for encouragement and the Indian Council of Agricultural Research, New Delhi, for partly funding this work. One of us (Y.C.J.) was a recipient of a fellowship under the United Nations Development Programme. The paper is N.D.R.I. publication No. 75-162.

\section{References}

Ahovcova, J.K. \& Odavic, R. (1969) A simple method for the quantitative analysis of phospholipids by thin layer chromatography. $J$. Chromat. 40, 90-96.
Clegg, E.D. \& Foote, R.H. (1973) Phospholipid composition of bovine sperm fractions, seminal plasma and cytoplasmic droplets. $J$. Reprod. Fert. 34, 379-383. 
Darin-Bennett, A., Poulos, A. \& White, I.G. (1973) A re-examination of the role of phospholipids as energy substrates during incubation of ram spermatozoa. J. Reprod. Fert. 34, 543-546.

Dittmer, J.C. \& Lester, R.L. (1964) A simple specific spray for the detection of phospholipids on thinlayer chromatograms. J. Lipid Res. 5, 126-127.

Folch, J., Lees, M. \& Sloane-Stanley, G.H. (1957) A simple method for the isolation and purification of total lipids from animal tissues. J. biol. Chem. 226, 497-509.

Freeman, C.P. \& West, D. (1966) Complete separation of lipid classes on single thin-layer plates. $J$. Lipid Res. 7, 324-327.

Gandhi, K.K. \& ANAND, S.R. (1975) Fructolysis and respiration of buffalo spermatozoa. J. Reprod. Fert. 45, 185-188.

Guraya, S.S. \& Sidhu, K.S. (1975) Lipid composition of buffalo spermatozoa: a cytochemical and biochemical study. J. Reprod. Fert. 42, 373-376.

JAIN, Y.C. \& ANAND, S.R. (1975a) The occurrence of sialoglycolipids in bull, buffalo and goat semen. J. Reprod. Fert. 42, 129-132.

JaIN, Y.C. \& ANAND, S.R. (1975b) Phospholipids of goat spermatozoa and seminal plasma. Biol. Reprod. 12, 393-395.

Johnson, L.A., Gerrits, R.J. \& Young, E.P. (1969) The fatty acid composition of porcine spermatozoa phospholipids. Biol. Reprod. 1, 330-334.

Kariyone, T. \& Hashimoto, Y. (1951) Paper partition chromatography of some organic bases by the method of N-methylation. Nature, Lond. 168, 739.

KAtes, M. (1967) Paper chromatography of phosphatides and glycolipids on silicic acid impregnated filter paper. In Chromatographic Analysis, Vol. 1, pp. 1-39. Ed. G. V. Marinetti. Marcel Dekker, Inc., New York.

Komarek, R.J., Picketr, B.W., Lanz, R.M. \& Jensen, R.G. (1964) Lipid composition of bovine spermatozoa and seminal plasma. J. Dairy Sci, 47, 531536.

Komarek, R.J., Pickett, B.W., Gibson, E.W. \& JENSEN, R.G. (1965a) Lipids of porcine spermatozoa, seminal plasma and gel. J. Reprod. Fert. 9, 131-136.

Komarek, R.J., Pickett, B.W., Gibson, E.W. \& LANZ, R.N. (1965b) Composition of lipids in stallion semen. $J$. Reprod. Fert. 10, 337-342.

LARDY, H.A. \& PhILIPS, P.H. (1941) The inter-relation of oxidative and glycolytic processes as source of energy for bull spermatozoa. Am. J. Physiol. 3, 602-609.

Layon, U., Volcani, R. \& Dannon, D. (1968) Deter- mination of dry matter percentage of ejaculated and epididymal bull spermatozoa after differential flotation. J. Reprod. Fert. 17, 151-153.

lovern, J.A., Olley, J., Hartree, E.F. \& Mann, T. (1957) The lipids of ram spermatozoa. Biochem. J. 67, 630-643.

MANN, T. (1960) Evaluation of semen by chemical analysis. In The Artificial Insemination of Farm Animals, 1st Indian edn, 1965, pp. 32-44. Ed. E. J. Perry. Oxford \& IBH publishing Co., Calcutta.

MARSh, J.B. \& WeInSteIN, D.B. (1966) Simple charring method for determination of lipids. J. Lipid Res. 7 , 574-576.

Miller, L.D., Mayer, D.T. \& Merilan, C.P. (1965) Lipid classes of bovine spermatozoa. J. Dairy Sci. 48, 395-398.

Pickett, B.W. \& Komarek, R.J. (1967) Lipid and dry weight of bovine seminal plasma and spermatozoa from first and second ejaculate. $J$. Dairy Sci. 50, $742-746$.

Poulos, A. \& White, I.G. (1973) The phospholipid composition of human spermatozoa and seminal plasma. J. Reprod. Fert. 35, 265-272.

Pursel, V.G. \& Graham, E.F. (1967) Phospholipid of bovine spermatozoa and seminal plasma. $J$. Reprod. Fert. 14, 203-211.

Renkonen, O., Gamberg, C.G., Simons, K. \& KarriAINEN, L. (1972) The lipids of plasma membranes and endoplasmic reticulum from cultured baby hamster kidney cells $\left(\mathrm{BHK}_{\mathbf{2}}\right)$. Biochim. biophys. Acta 255, 66-78.

Rouser, G., Fleischer, S. \& Yamamoto, A. (1970) Two dimensional thin-layer chromatographic separation of polar lipids and determination of phospholipids by phosphorus analysis of spots. Lipids 5 , 494-496.

Schmid, H.H.O. \& Mangold, H.K. (1966) Alkoxy lipids - "neutral plasmalogens". Biochim. biophys. Acta 125, 182-184.

SiNGH, P. (1967) Studies on certain aspects of metabolic activity and livability of buffalo spermatozoa in relation to climate and semen diluents. Ph.D. thesis, Agra University.

Skidmore, W.D. \& EnTEnman, C. (1962) Two dimensional thin-layer chromatography of rat liver phosphatides. J. Lipid Res. 3, 471-475.

VASKovsky, V.E. \& SVetashev, V.I. (1972) Phospholipid spray reagents. J. Chromat. 65, 451-453.

Vishwanathan, C.V., Philips, F. \& Lundberg, W.O. (1968) Two dimensional reaction thin-layer chromatography in the analysis of phosphatide plasmalogen. J. Chromat. 35, 66-71. 